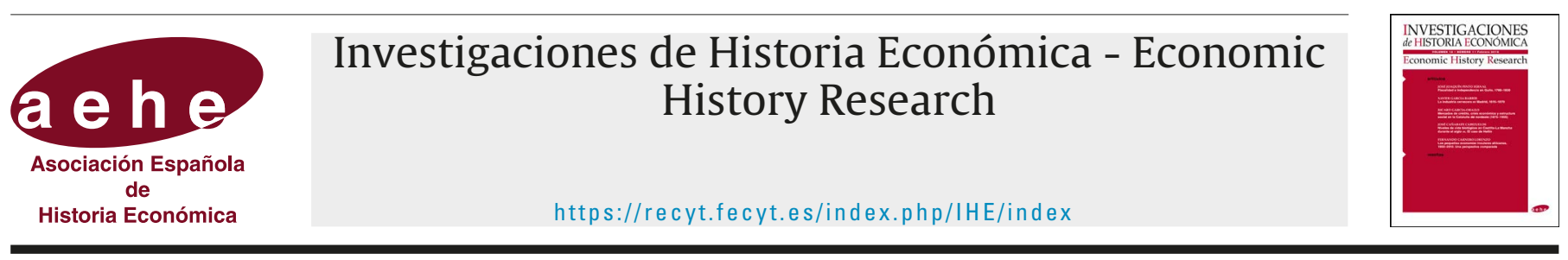

Reseña

\section{Paolo Di Martino, Andrew Popp and Peter Scott (eds.). People, Places and Business Cultures. Essay in Honour of Francesca Carnevali. Woodbridge, The Boydell Press, 2019, 266 págs., ISBN: 978-1-78327-212-9.}

El volumen editado por Paolo Di Martino, Andrew Popp y Peter Scott se propone recordar, honrar y perpetuar el trabajo de Francesca Carnevali (1964-2013), volviendo sobre los pasos de los temas y debates principales a los cuales ella dedicó su trayectoria investigadora, precozmente interrumpida. Un amplio grupo de ilustres estudiosos, recogiendo la herencia de la investigadora, presenta nuevas investigaciones sobre la historia económica británica y europea de los siglos xIx y xx. Para ello utilizan como hilo conductor lo que identifican como su principal legado: la necesidad de volver a moldear la historia económica como una disciplina en la que las personas importan y marcan la diferencia, siendo los agentes que en el mundo real conectan economía y sociedad dando forma a los distintos tipos de instituciones, y creando y definiendo en el tiempo lo que es el «valor».

El libro se divide en cuatro partes. La primera de ellas comprende una introducción de los coordinadores, que sintetiza el objetivo del volumen y sus principales contenidos, y un capítulo de reflexión a cargo de Paolo Di Martino, que pasa a reseñar de forma particular el legado tanto profesional como personal de Francesca Carnevali. En particular, el capítulo de Di Martino trata los principales temas y debates de los que se ocupó la historiadora a lo largo de su trayectoria académica, entre los cuales cabe mencionar el supuesto declive de la economía británica en las décadas comprendidas entre 1870 y la Primera Guerra Mundial, el papel jugado por la economía política en la comprensión de la evolución histórica del sistema bancario y su heterogeneidad en Europa, el funcionamiento de los distritos industriales, el estudio de la idea de lujo, la atención en la utilización de elementos sociales y culturales para explicar el comportamiento de los agentes económicos y, finalmente, el análisis de las industrias de producción de bienes "menores", como por ejemplo muebles o instrumentos musicales, que hasta el momento apenas habían sido objeto de estudio.

La segunda parte del volumen se centra en temas específicos a los que Francesca Carnevali contribuyó directamente, y se compone de cinco capítulos. El primero de ellos, escrito por Andrew Popp, se inspira en el trabajo de la estudiosa sobre la acción social en el distrito industrial de joyas de Providence. En particular, el capítulo trata del distrito industrial mercantil de Liverpool y se pregunta por el motivo por el cual los comerciantes de algodón de Liverpool seguían insistiendo en comerciar al aire libre y en suelo público durante muchos años, a pesar de que ya dispusieran de una sala de comercio de algo- dón construida con ese objetivo, y afirma que se debería considerar este comportamiento como una «acción simbólica» que les permitía reclamar sus derechos y su legitimidad. El segundo capítulo, escrito por Alberto Rinaldi y Anna Spadavecchia, estudia el complejo sistema financiero desarrollado en Italia para la financiación de la pequeñas y medianas empresas y los distritos industriales, y subraya el papel jugado por la Banca d'Italia, que después de 1945 favoreció la apertura de nuevas filiales a nivel regional con el objetivo de financiar a las pequeñas y medianas empresas locales, y analiza la historia de la institución Artigiancassa (Banco Artesano), fundada en 1947 para proporcionar crédito a las empresas artesanas. El tercer capítulo, escrito por Leslie Hannah, analiza el impacto del sistema financiero británico anterior a la Primera Guerra Mundial sobre la estructura industrial del país, constituida por pequeñas y grandes empresas y compañías multinacionales, y afirma que mientras los factores que ponían supuestamente en declive la economía británica habrían afectado también a otros países competidores en las décadas siguientes, la estructura de la economía británica era, en cambio, mucho menos apta para tratar con problemas típicos de una época de deglobalización, como fue el periodo de entreguerras. El cuarto capítulo, escrito por Peter Scott y James Walker, estudia la emergencia de la distribución a gran escala, la difusión de estrategias de marketing de masa y la gradual disminución de las demarcaciones entre clases sociales en la Inglaterra del periodo de entreguerras. También examina casos emblemáticos en la tendencia hacia una distribución comercial minorista accesible a todas las clases sociales como Woolworths, Marks \& Spencer and British Home Stores. El quinto y último capítulo de la segunda parte del volumen, escrito por Lucy Newton, emerge directamente de un proyecto en el cual la autora había comenzado a trabajar con Francesca Carnevali, y que desgraciadamente no se pudo acabar con ella, sobre la producción de los bienes habitualmente presentes en las casas de la época victoriana y eduardiana, como por ejemplo muebles, cristales, cerámicas, cuchillerías y otros objetos similares, y estudia en particular la industria de producción de pianos desde una perspectiva microeconómica.

La tercera parte del libro, compuesta por cuatro capítulos, analiza cuestiones metodológicas y estudia las interacciones entre las diferentes ramificaciones de la historia. El capítulo escrito por Michael Hilton se pregunta acerca de cómo la última edición del manual 20th Century Britain: Economic, Cultural and Social Change, coordinada por Francesca Carnevali y Julie-Marie Strange en 2007, podría ser actualizada. En particular se pregunta qué nuevos temas deberían ser incluidos y cuáles han sido las principales innovaciones y líneas de investigación en los últimos diez años. Kenneth Lipartito, en el segundo capítulo de esta sección del libro, investiga cómo economistas e historiadores han aplicado conceptos como el de trust, capital social y embe- 
dednness para entender cómo los actores han operado en algunas circunstancias de forma cooperativa o sin perseguir un interés exclusivamente individual. Inspirándose en los trabajos de Francesca Carnevali sobre los distritos industriales de joyas de Providence y Birmingham, él sugiere que el concepto de capital social no se debe considerar tanto como una estructura general, sino como un proceso que puede ser modificado continuamente, con ganadores y perdedores. De la misma manera, el trust no se debería considerar en términos utópicos, sino como una relación inestable entres actores que corren un riesgo cuando interactúan. El capítulo de Chris Wickham estudia la relación entre historia económica y microhistoria, señalando cómo la microhistoria ha sido probablemente el ámbito al cual los historiadores italianos han contribuido más desde mediados del siglo xx y poniendo el trabajo de Francesca Carnevali sobre los productores de joyas de Providence como ejemplo de cómo debería ser la microhistoria. El último capítulo de esta parte del volumen, escrito por Andrea Colli, analiza la reciente renovación del interés sobre el tema de la empresa europea, también en el marco del debate sobre la variedad de capitalismos, y explora las diferencias entre empresas norteamericanas, europeas y asiáticas (con sus variantes regionales), no solo en términos de similitudes y diferencias entre arquetipos de capitalismo, sino también del impacto que cada modelo de capitalismo ha tenido sobre los resultados económicos de las compañías y, por lo tanto, de sus respectivas naciones.

En la cuarta y última parte del libro se encuentra un capítulo, escrito por los coordinadores, que incluye las principales conclusiones y resume el legado de Francesca en torno a tres áreas principales: un enfoque de historia económica que considera la importancia de las personas, la importancia de adoptar una metodología bottom-up (de abajo hacia arriba) y la necesidad de utilizar una perspectiva más ecléctica y abierta al analizar y explicar los fenómenos históricos. Una lista completa de las publicaciones de Francesca Carnevali cierra esta última parte y el volumen.

El libro se lee con facilidad y placer gracias a la alta calidad de los trabajos y al gran interés y actualidad de los argumentos y debates de los que Francesca Carnevali se ocupó con notable agudeza y que los autores tratan con eficacia y perspectiva futura. La amplia variedad de temas incluidos en el volumen, además de despertar admiración por el trabajo que la estudiosa había llevado y estaba llevando a cabo, hace del libro una lectura de gran interés no solo para historiadores de la empresa, sino también por historiadores económicos y, más en general, estudiosos de disciplinas afines. El volumen representa, por lo tanto, un instrumento muy útil y de notable importancia para impulsar ese enfoque ecléctico y flexible que Francesca Carnevali sugirió en sus trabajos y que los coordinadores han identificado como uno de sus principales legados.

Veronica Binda Universidad Bocconi (Milán)

https://doi.org/10.33231/j.ihe.2020.01.008 